\author{
Marquette University \\ e-Publications@Marquette
}

Electrical and Computer Engineering Faculty Research and Publications

Electrical and Computer Engineering,

Department of

$5-25-2017$

\title{
A Current-Dependent Switching Strategy for Si/SiC Hybrid Switch- Based Power Converters
}

Jiangbiao He

Marquette University

Ramin Katebi

Marquette University

Nathan Weise

Marquette University, nathan.weise@marquette.edu

Follow this and additional works at: https://epublications.marquette.edu/electric_fac

Part of the Computer Engineering Commons, and the Electrical and Computer Engineering Commons

\section{Recommended Citation}

$\mathrm{He}$, Jiangbiao; Katebi, Ramin; and Weise, Nathan, "A Current-Dependent Switching Strategy for Si/SiC Hybrid Switch-Based Power Converters" (2017). Electrical and Computer Engineering Faculty Research and Publications. 294.

https://epublications.marquette.edu/electric_fac/294 
Marquette University

\section{e-Publications@Marquette}

\section{Electrical Engineering Faculty Research and Publications/College of Engineering}

This paper is NOT THE PUBLISHED VERSION; but the author's final, peer-reviewed manuscript. The published version may be accessed by following the link in the citation below.

IEEE Transactions on Industrial Electronics, Vol. 64, No. 10 (2017): 8344-8352. DOI. This article is (C) Institute of Electrical and Electronics Engineers (IEEE) and permission has been granted for this version to appear in e-Publications@Marquette. Institute of Electrical and Electronics Engineers (IEEE) does not grant permission for this article to be further copied/distributed or hosted elsewhere without the express permission from Institute of Electrical and Electronics Engineers (IEEE).

\section{A Current-Dependent Switching Strategy for Si/SiC Hybrid Switch-Based Power Converters}

Jiangbiao He Department of Electrical and Computer Engineering, Marquette University, Milwaukee, WI Ramin Katebi Department of Electrical and Computer Engineering, Marquette University, Milwaukee, WI Nathan Weise

Department of Electrical and Computer Engineering, Marquette University, Milwaukee, WI

\footnotetext{
Abstract:

Hybrid switches configured by paralleling Silicon (Si) Insulated Gate Bipolar Transistors (IGBT) and Silicon Carbide (SiC) Metal-Oxide Semiconductor Field-Effect Transistors (MOSFET) have been verified to be a high-efficiency cost-effective device concept. In this paper, a current-dependent switching strategy is introduced and implemented to further improve the performance of Si/SiC hybrid switches. This proposed switching strategy is based on a comprehensive consideration of reducing device losses,
} 
reliable operation, and overload capability. Based on the utilization of such Si/SiC hybrid switches and the proposed switching strategy, a $15-\mathrm{kW}$ single-phase $\mathrm{H}$-bridge inverter prototype was implemented and tested in the laboratory. Simulation and experimental results are given to verify the performance of the hybrid switches and the new switching strategy.

\section{IEEE Keywords}

Switches, Silicon carbide, Insulated gate bipolar transistors, MOSFET, Silicon, Zero voltage switching, Switching loss

\section{SECTION I.}

\section{Introduction}

The recent emerging wide bandgap (WBG) devices provide an attractive solution to improve power converter efficiency and power density by reducing semiconductor losses, operating at higher switching frequencies, and higher temperatures in many different applications. ${ }^{1-4}$ However, the present market price of WBG devices, such as Silicon Carbide (SiC) MOSFETs, is still much higher than that of their Silicon (Si) counterparts. As a result, power converters consisting of pure WBG devices significantly increase the system cost, especially for high-power converters which typically require a large number of power devices. Therefore, explorations on leveraging the beneficial characteristics of

the WBG devices while minimizing the quantity of WBG devices to be used in power converters will be of great necessity to reduce system cost for the present industry.

On the other hand, paralleling semiconductor devices has been a common approach to achieve higher device current ratings in industrial power converters. ${ }^{5-8}$ Different devices can also be parallel connected together to configure a hybrid switch for fully utilizing their respective characteristics, in addition to simply improving the current ratings. ${ }^{9-18}$ One of the earliest hybrid device concepts is the utilization of SiC Schottky barrier diodes (SBDs) as the antiparallel freewheeling diode for Si IGBTs, which has been widely used in industry in the past decade due to the lower diode reverse recovery losses and IGBT turn-on losses compared to employing the conventional Si fast recovery diodes. ${ }^{9}$ In, ${ }^{10,12,13}$ soft-switching of Si IGBTs with the assistance of parallel-connected Si MOSFETs was investigated for bridge-type power converters, as shown in Fig. 1(a) . In, ${ }^{11}$ to reduce device conduction losses, a Si MOSFET was connected in parallel with a Si IGBT to replace conventional free-wheeling $p$-i$\mathrm{n}$ diode, as shown in Fig. 1 (b). In, ${ }^{14}$ a combination of IGBTs and MOSFETs in a full-bridge configuration is utilized to increase the efficiency of a dual-active-bridge (DAB) converter in a solid state transformer. In the work presented in, ${ }^{14}$ the hybrid device configuration enables zero-current switching (ZCS) of the IGBTs which results in a higher efficiency of the DAB converter. Recently, with the presence of SiC MOSFETs in the semiconductor device market, hybrid switches based on parallel connections of conventional Si IGBT and SiC MOSFET were also studied. ${ }^{15-18}$ It was shown that this new breed of hybrid switches combine the advantages of Si IGBT and SiC MOSFET at a much lower cost than using pure SiC MOSFETs. However, investigations on developing switching strategies for such Si/SiC hybrid devices with a comprehensive consideration of device losses, reliable operation, and overload capability have been absent from the literature. Specifically, unlike the synchronous switching in paralleling the same type of power devices, the operation of the Si/SiC hybrid switches requires the consideration of the switching characteristics of each type of devices. For instance, SiC MOSFET has a much faster switching speed than Si IGBTs. If no measures are taken in the switching strategy, Si IGBTs 
will always experience large turn-off losses in the hybrid switch due to its slower turn-off speed than SiC MOSFETs. In other words, the characteristic of low switching losses with SiC MOSFETs may not be fully utilized in the hybrid switches. More importantly, at a heavy load operating condition of power converters, the faster turn-on of the SiC MOSFETs poses a reliability concern to such SiC devices because all the load current will flow through the devices during the prior turn-on instant. In addition, to reduce system cost, more IGBTs and less SiC MOSFETs are preferred to be parallel connected in the hybrid switches. As a result, IGBTs have higher overload capability in the hybrid structure, which is more suitable to be utilized in heavy load or overload operating regions. With such considerations, a comprehensive switching strategy needs to be developed to reduce device losses, guarantee the reliable operation, and improve the system overload capability.

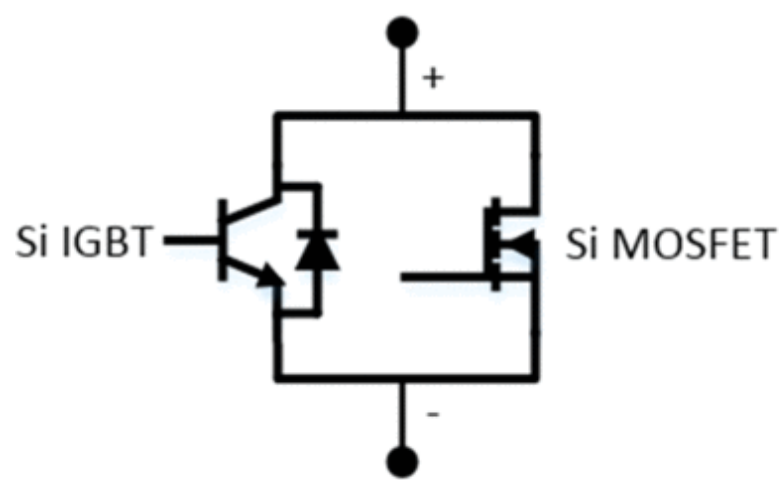

(a)

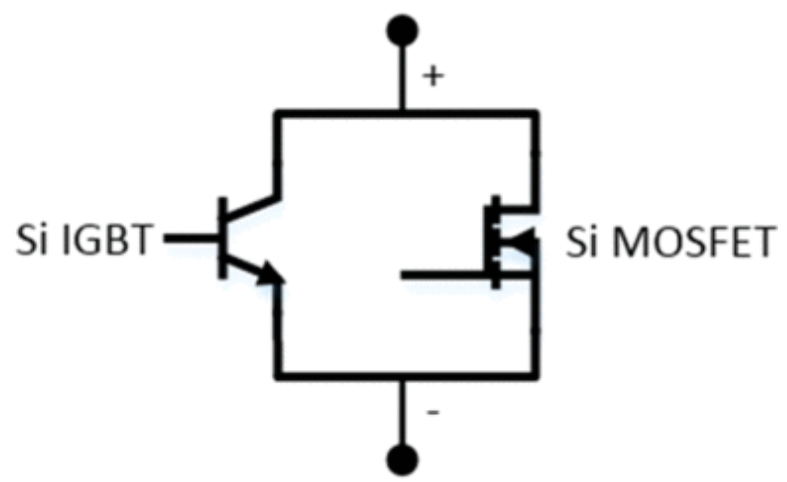

(b)

Fig. 1. IGBT/MOSFET hybrid switches: (a) MOSFET is used for ZVS soft switching, (b) MOSFET is used to replace the antiparallel diode.

Since a high-performance switching strategy of the $\mathrm{Si} / \mathrm{SiC}$ hybrid switches requires the consideration of the operating characteristics of each switching device in the hybrid configuration, such as their output characteristics ( $I-V$ curves) and switching characteristics, it is necessary to analyze these device characteristics first before the discussion of any novel switching strategies for the Si/SiC hybrid switches.

\section{SECTION II.}

\section{Characteristics of the Si/SiC Hybrid Switches}

Different number of SiC devices used in hybrid switches results in different output characteristics. The more SiC devices parallel connected in the hybrid switches will yield the lower conduction and switching losses, but the cost of the hybrid switches will increase dramatically according to the present market price of SiC devices. In order to limit the cost increase caused by SiC devices, SiC MOSFET with lower current ratings is recommended here for the configuration of the hybrid switches. In this paper, the hybrid switches are configured by one Si IGBT (IRG7PH42U, $1200 \mathrm{~V} / 30 \mathrm{~A}^{19}$ ) and one SiC MOSFET (CREE C2M0160120D, $1200 \mathrm{~V} / 10 \mathrm{~A}^{20}$ ), in which the current rating ratio of the IGBT to SiC MOSFET is 3:1. Accordingly, the hybrid switches will be rated at $1200 \mathrm{~V} / 40 \mathrm{~A}$ at a case temperature of $T_{C}=100 \circ \mathrm{C}$. The conduction loss and the switching loss characteristics of this customized hybrid switch will be discussed as follows. 


\section{A. Conduction Loss of the Hybrid Switch}

The conduction loss of the hybrid switch is determined by its resultant output characteristics of all the paralleled devices. The output characteristics of the IGBT, SiC MOSFET, and the configured hybrid switch are shown in Fig. 2. As can be seen in Fig. 2, the $I-V$ curves of the IGBT and SiC MOSFET have a cross point at $(1.25 \mathrm{~V}, 8 \mathrm{~A})$. This indicates that most of the current will flow through MOSFET for load current below $8 \mathrm{~A}$. For load current above $8 \mathrm{~A}$, IGBT will dominate the sharing of the load current. As a result, the $I-V$ curve of the $\mathrm{Si} / \mathrm{SiC}$ hybrid switch, shown in the green dashed curve in Fig. 2, combines the low conduction loss of MOSFET at low current and low conduction loss of IGBT at high current.

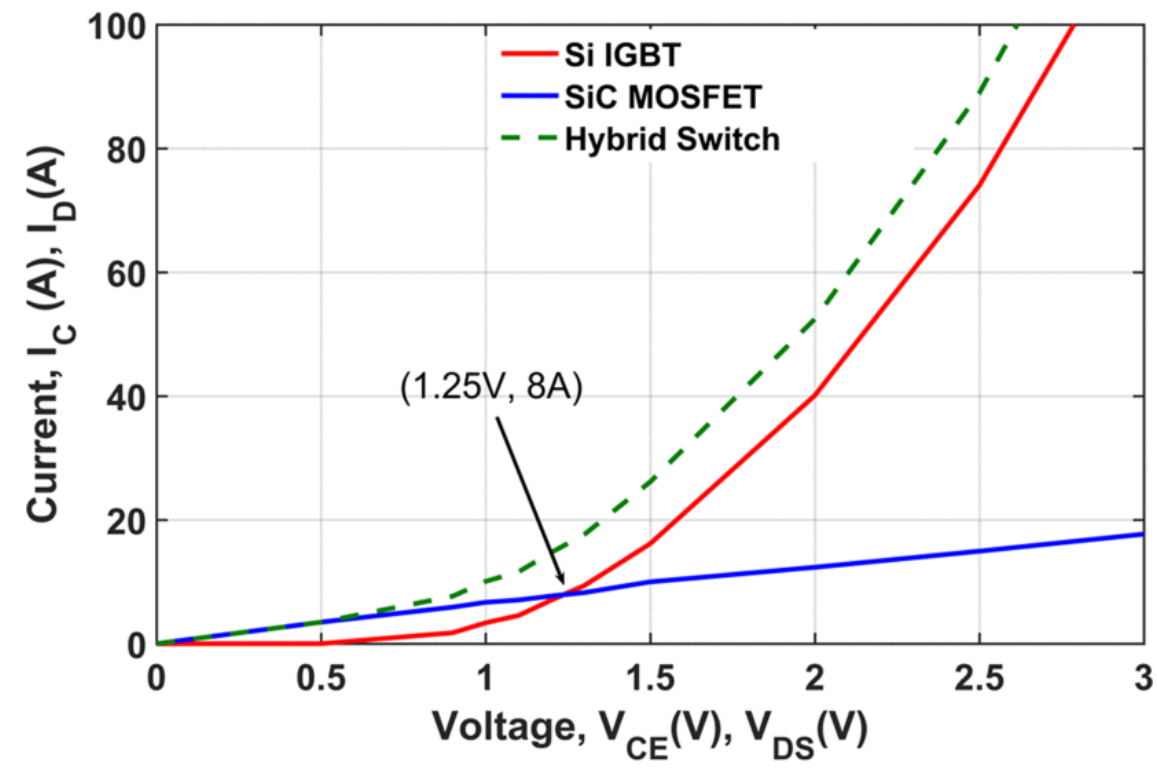

Fig. 2. Output characteristics $\left(I_{C}, I_{D}\right.$ versus $\left.V_{\mathrm{CE}}, V_{\mathrm{DS}}\right)$ of $\mathrm{Si}$ IGBT, SiC MOSFET, and Si/SiC hybrid switch at $T_{j}=$ $25{ }^{\circ} \mathrm{C}$.

\section{B. Switching Loss of the Hybrid Switch}

It is known that SiC devices have much lower switching losses than their Si counterparts due to the fast switching speed and the related material property. Therefore, the switching losses of hybrid switches are dominated by the switching losses from the IGBTs, which can be significantly reduced if all the turn-on and turn-off actions are undertaken by the SiC devices in the hybrid switches. With such motivation, a zero-voltage switching (ZVS) pattern for the Si/SiC hybrid switches is proposed and shown in Fig. 3, and the associated switching voltage and current waveforms of the hybrid switches are illustrated in Fig. 4. As can be seen that, the MOSFET is turned on earlier but turned off later compared to the IGBT; thus, a quasi-ZVS can be achieved in the IGBT at the turn-on and turn-off instants due to the very low on-state voltage across the IGBT. However, the safe operating area (SOA) of the SiC devices should be considered during the implementation of such a switching pattern for the hybrid switches. Otherwise, the presence of the large current spikes during the prior turn-on and later turnoff instants of the SiC MOSFET may damage the device by overcurrent. 


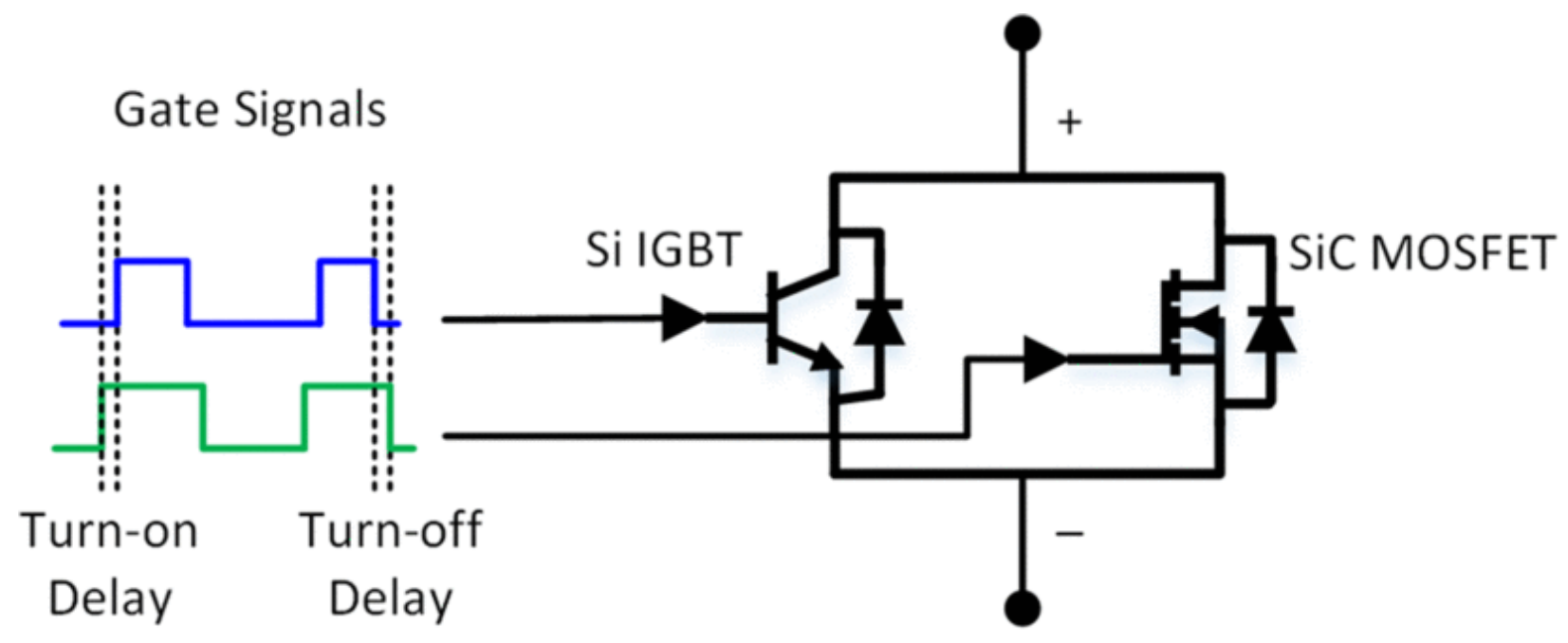

Fig. 3. Proposed ZVS switching pattern for Si/SiC hybrid switches.

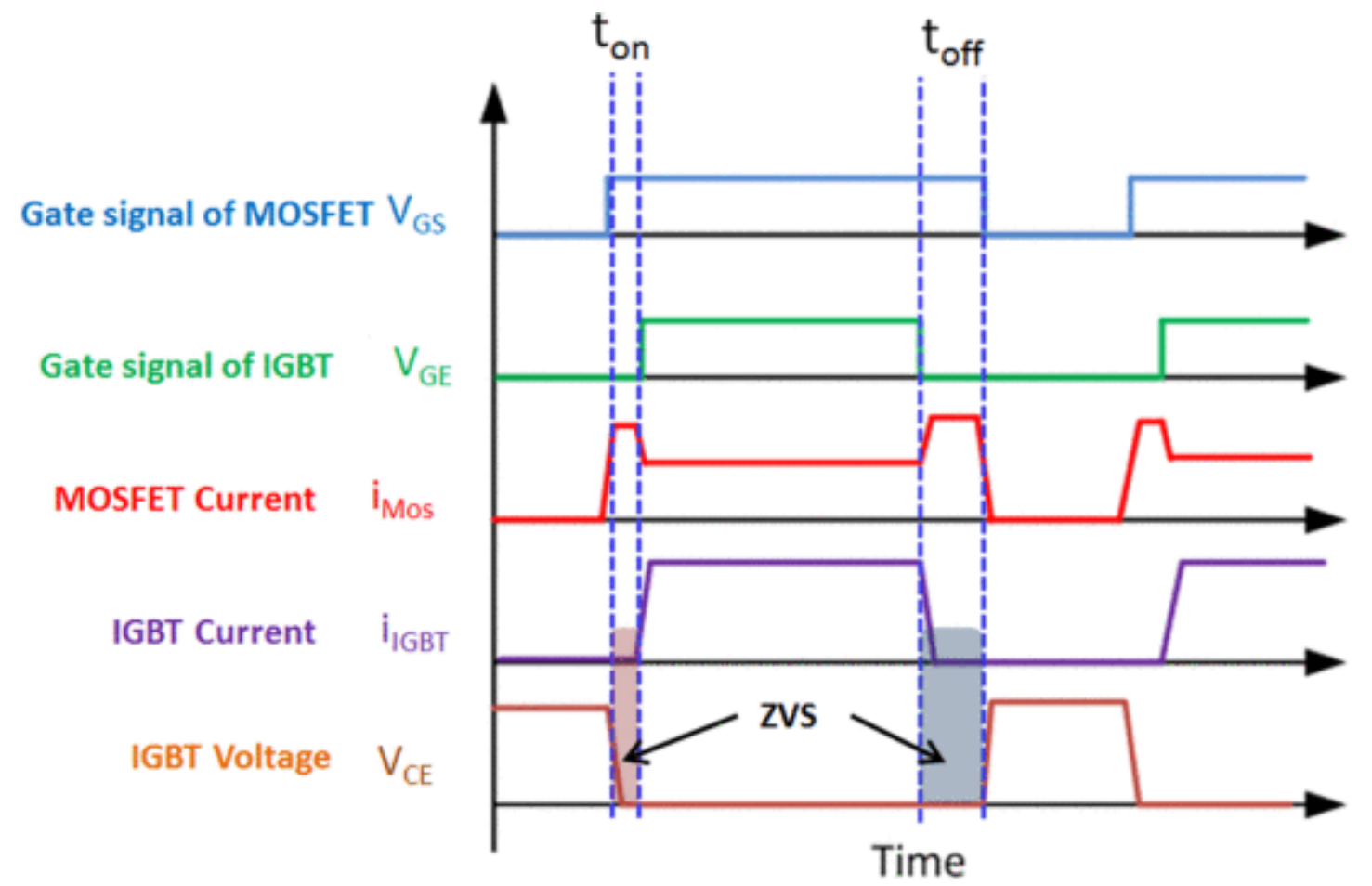

Fig. 4. Graphic illustration of the turn-on and turn-off signals of the Si/SiC hybrid switches based on the ZVS switching pattern.

\section{SECTION III.}

\section{Proposed Current-Dependent Switching Strategy for Si/SiC Hybrid Switches} A high-performance switching strategy for hybrid switches requires a comprehensive consideration of reducing semiconductor device losses and device overcurrent capabilities. In this paper, a novel switching strategy based on the time-varying load current within a fundamental sinusoidal cycle is developed to fully utilize the attractive characteristics of each type of device in the hybrid structure. The main motivation here is to reduce the device losses, guarantee safe operation of each parallel device, and improve the overcurrent capability of the hybrid switches. This new switching strategy 
consists of three patterns for different levels of load current, and each switching pattern is introduced as follows.

\section{A. Pattern I: Only SiC mosfet is Switched}

In Pattern I, only the SiC MOSFET is switched, and the Si IGBT is kept in normally-off state. This switching pattern is applied when the load current is below the boundary load current value $I_{1}$, which is determined by the corresponding $\mathrm{SiC}$ device current value in the $I-V$ curve when its drain-source voltage is equal to the Si IGBT collector-emitter saturation voltage. When the hybrid device current is below this boundary current, the voltage drop across the SiC device is not high enough to conduct the IGBT. Therefore, only SiC device is conducted. This pattern is especially beneficial for the applications where light load condition is the typical operating mode. For instance, in data center applications, most uninterruptible power supply converters typically operate in the range of $20-40 \%$ load conditions. $^{21}$

\section{B. Pattern II: SiC mosfet is Turned on Earlier and Turned off Later}

In Pattern II, the SiC MOSFET is turned on earlier and off later compared to the Si IGBTs. This switching pattern is applied when the load current is above the critical value $I_{1}$, but below the maximum SOA current $I_{2}$ of the SiC MOSFET. In this pattern, all the switching on and off are handled by the SiC MOSFET to achieve the minimum switching losses for the hybrid switch, as shown in Figs. 3 and 4. More specifically, SiC MOSFET is turned on earlier than the IGBT during the hybrid switch turn-on process to achieve ZVS for the subsequent switching-on of IGBTs. Similarly, the SiC MOSFET is turned off later during the turn-off process to achieve ZVS for the prior switching-off of the IGBTs. Considering the faster switching speed of the MOSFET, turn-on and turn-off delays between the MOSFET and the IGBT are required to ensure that the MOSFET is fully turned on before the IGBT is turned on and the IGBT is fully turned off before the MOSFET is turned off. The specific values of time delays are determined by the devices' actual switching speed and the deadtime between two complementary hybrid switches in a converter phase leg. For instance, if the turn-on time of a SiC MOSFET is $50 \mathrm{~ns}$, then the turn-on delay can be set as 100 ns to ensure the MOSFET is fully turned on. However, this time delay should not be set longer than the deadtime between the upper switch and bottom switch in one half bridge, to avoid any shoot-through fault of the dc bus. Additionally, the longer the time delay, the more thermal stress the SiC device in the conduction mode will experience. Typically, the delay just needs to be a little longer than the actual turn-on time or turn-off time of the device that is switched on/off earlier.

It should be noted that there are generally "current spikes" during SiC device turn-on and turn-off instants. As mentioned before, this is because that the total load current flows through the SiC MOSFET during the turn-on and turn-off delays. Therefore, transient thermal analysis is recommended to determine the boundary load current value $I_{2}$ so that the SiC devices are capable of conducting high peak current for a very short period of time (typically, less than one microsecond).

\section{Pattern III: IGBT is Turned on Earlier and off Later}

In Pattern III, IGBTs are turned on earlier and off later. The purpose of using this switching pattern is to ensure that the load current can be switched safely by the IGBTs when it exceeds the boundary load current value $I_{2}$ or SOA of the SiC devices. Considering that IGBTs have much lower market price, more IGBTs are recommended to be parallel connected in the hybrid switches, which indicates a larger current rating and higher overload capabilities of IGBTs than the SiC MOSFETs. Therefore, IGBTs are 
turned on earlier and turned off later for the load current beyond the SOA of SiC devices to guarantee device reliability.

With these three switching patterns discussed above, a comprehensive current-dependent switching strategy for the 1200-V Si/SiC hybrid switches used in a single-phase $\mathrm{H}$-bridge inverter is developed in this paper, in which all the three patterns introduced above are alternatively utilized based on the changing amplitude of the load current. Fig. 5 depicts the integration of the proposed switching strategy in a sinusoidal load current cycle. Different patterns are selected based on the instantaneous load current values in each sinusoidal cycle to minimize the semiconductor losses, maintain the device safe operation ratings, and meet the system overload requirements.

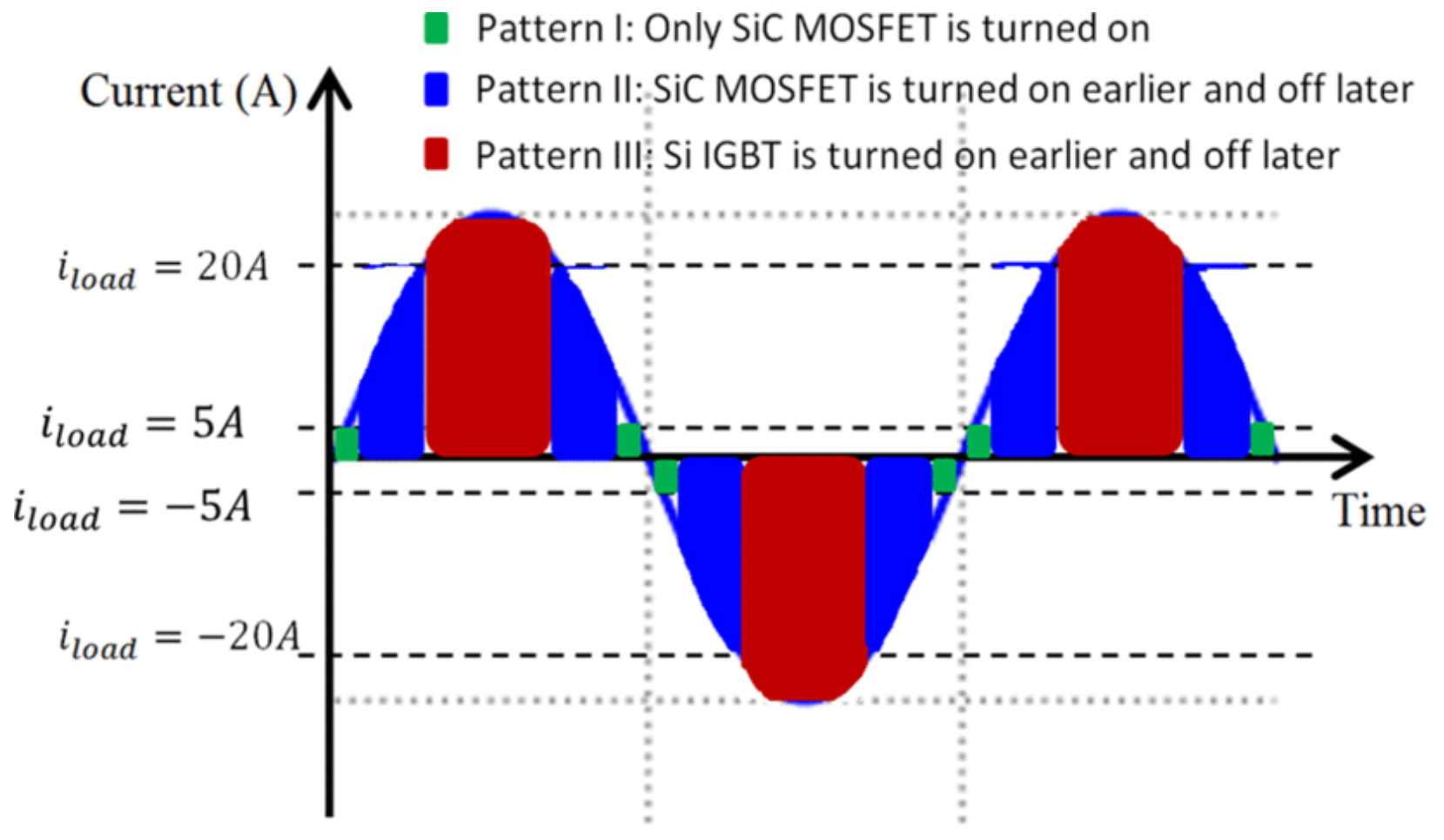

Fig. 5. Proposed current-dependent switching strategy for Si/SiC hybrid switches in sinusoidal load current conditions.

Procedures of implementing such current-dependent switching pattern for a 1200-V hybrid switch are given as follows, in which the specific current boundary values are determined based on the device ratings and thermal analysis.

1. For light load current, $i_{L} \leq 5 \mathrm{~A}$, Pattern I is applied and only SiC MOSFET is switched. The value of $5 \mathrm{~A}$ is the SiC MOSFET current point when its drain-source voltage is equal to the IGBT collector-emitter saturation voltage, according to its I-V curve at a junction temperature of $T_{j}=150 \quad{ }^{\circ} \mathrm{C}$. Since the SiC device has much lower conduction and switching losses than Si IGBTs in this current region, only switching SiC devices can significantly reduce the semiconductor losses of the hybrid switches and improve the light-load efficiency of the inverter.

2. For load current in the range of $5 \mathrm{~A}<i_{L}<20 \mathrm{~A}$, Pattern II is applied. In this pattern, the SiC device is turned on earlier and turned off later as illustrated in Fig. 4 . Since the load current is above the boundary load current value $I_{1}(5 \mathrm{~A})$, IGBT can be turned on to share the current with SiC devices and reduce the total conduction losses. Furthermore, this switching pattern enables the ZVS operation of IGBT devices, so all the switching losses only occur in the SiC MOSFETs, which is significantly lower than 
Si IGBTs' switching loss at the same current. The upper limit of this current region $\left(I_{2}=20 \mathrm{~A}\right)$ is based on the consideration of both transient thermal analysis and SOA characteristics from the SiC device datasheet. ${ }^{19}$

3. For load current in the range of $i_{L} \geq 20 \mathrm{~A}$, Pattern III is applied, in which the Si IGBTs are switched on earlier and switched off later to guarantee the safe operation of the SiC devices as well as meeting the system overload requirements.

\section{SECTION IV.}

\section{Simulation Results}

In this section, a single-phase H-bridge inverter based on using the 1200-V Si/SiC hybrid switches as well as the proposed current-dependent switching strategy is simulated in PLECS software environment. The circuit topology of the $\mathrm{H}$-bridge inverter is shown in Fig. 6 . In the simulation, the inverter dc-bus voltage is set as $600 \mathrm{~V}$, and the switching frequency is $10 \mathrm{kHz}$. The rated power of the inverter is sized at $15 \mathrm{~kW}$, and the rated load current is $20 \mathrm{~A}$ RMS. Three different representative load current points, namely, $5 \mathrm{~A}$ RMS, $10 \mathrm{~A}$ RMS, and $20 \mathrm{~A} \mathrm{rms,} \mathrm{are} \mathrm{simulated,} \mathrm{and} \mathrm{the} \mathrm{corresponding}$ switching voltage and current waveforms are shown in Figs. 7, 8, and 9, respectively. In Fig. 7, it can be seen that the load current of 5 A RMS, only flows through the SiC MOSFET, which is because that the voltage across the IGBT is lower than its collector-emitter saturation voltage for turn-on. In Fig. 8, with a load current of 10 A RMS, the switching pattern II is applied, and it can be seen that ZVS is achieved for the IGBT turn-on and turn-off instants with the assistance of SiC MOSFET, as illustrated by the blue shaded bar in Fig. 8. In Fig. 9, with a larger load current of 20 A RMS, the Si IGBT is turned on earlier and turned off later to protect the SiC MOSFET from overcurrent damage. With an integration of this current-dependent switching strategy into each sinusoidal load current cycle, thermal simulation of the $\mathrm{H}$-bridge inverter was conducted and the efficiency curve is shown in Fig. 10. Specifically, in the thermal simulation, the whole Si/SiC hybrid inverter was enclosed by a virtual heat sink, so the heat sink absorbs all the thermal losses dissipated by the power devices. The device loss data is obtained and further processed to calculate the inverter efficiency. Meanwhile, the heat sink defines an isotherm environment and propagates its temperature to the components which it encloses. Fig. 10 shows that the efficiency of the $\mathrm{H}$-bridge inverter can be boosted by as much as $1.52 \%$ by using the $\mathrm{Si} / \mathrm{SiC}$ hybrid switches, in comparison to use pure Si IGBTs. Moreover, it should be noticed in Fig. 10 that the larger efficiency gain at light load than that at nominal load if using Si/SiC hybrid switches results from the fact that the IGBT experiences hard switching at rated load or overload conditions. However, at heavy load conditions, the conduction losses of the hybrid switches are still lower than that of the pure IGBT devices at the same ratings, which leads to slightly higher inverter efficiency. The related experimental results will be given in Section $V$ for further investigation. 


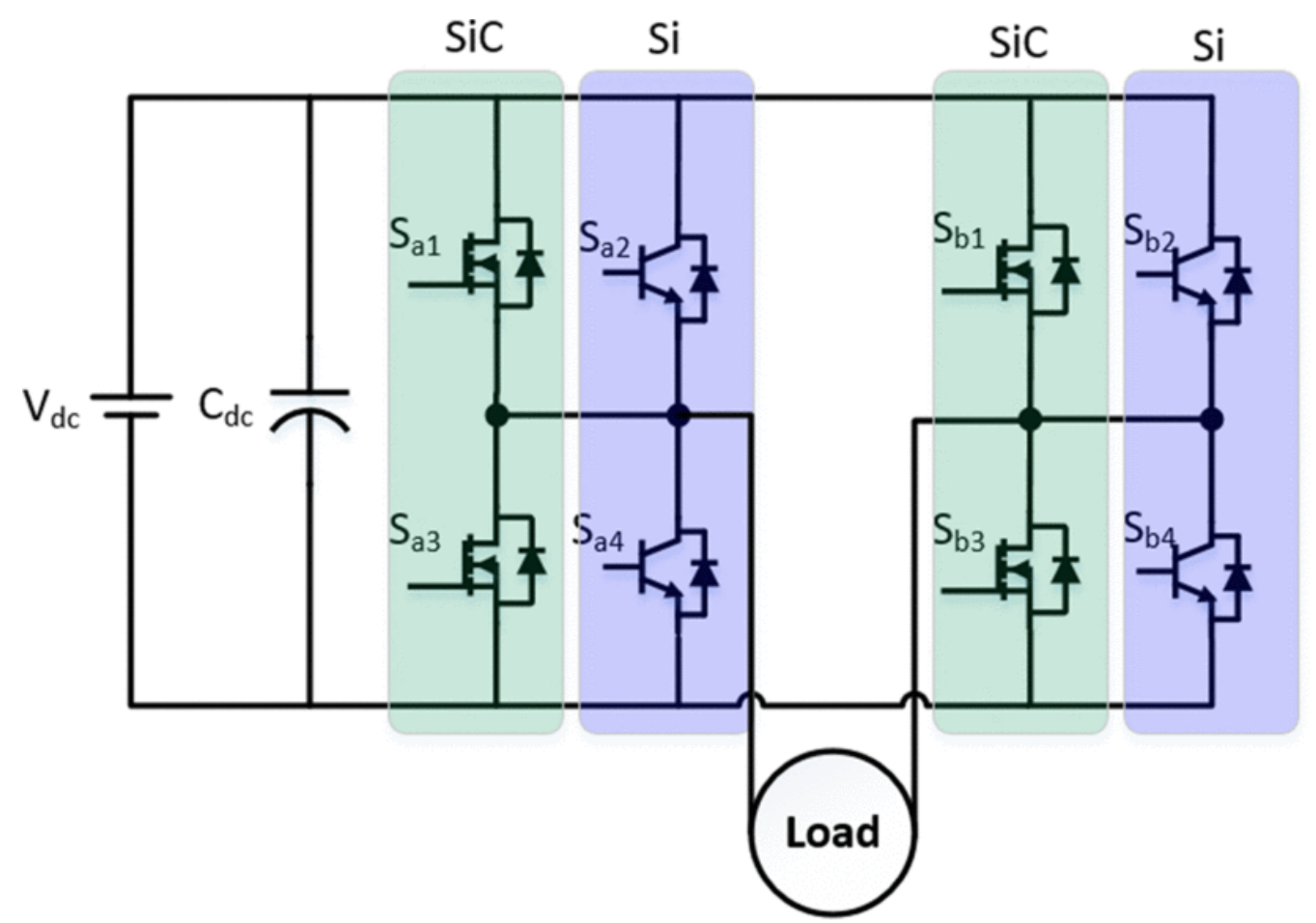

Fig. 6. H-bridge inverter based on using the Si/SiC hybrid switches.
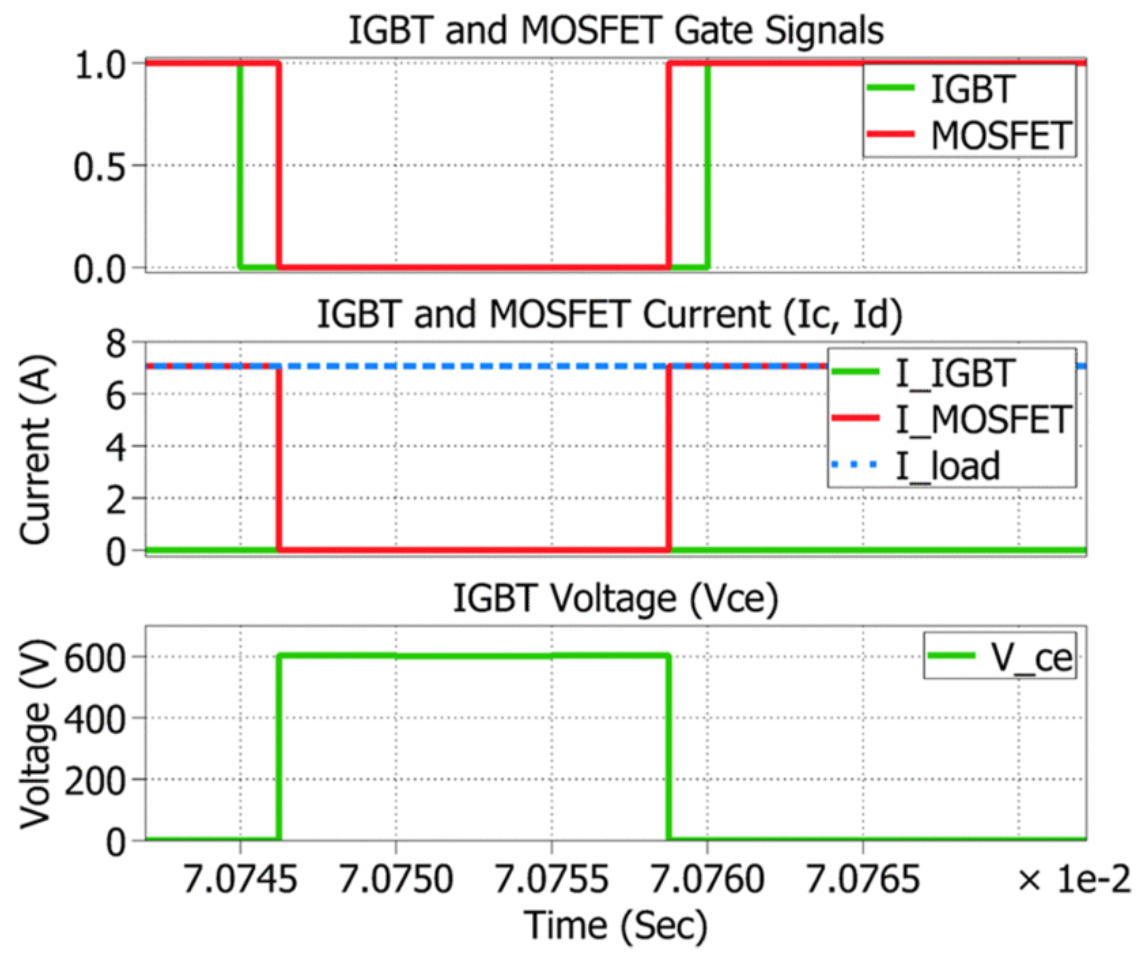

Fig. 7. Simulated switching voltage and current waveforms of the hybrid switch at a load current of 5 A RMS ( $25 \%$ of the nominal load). 


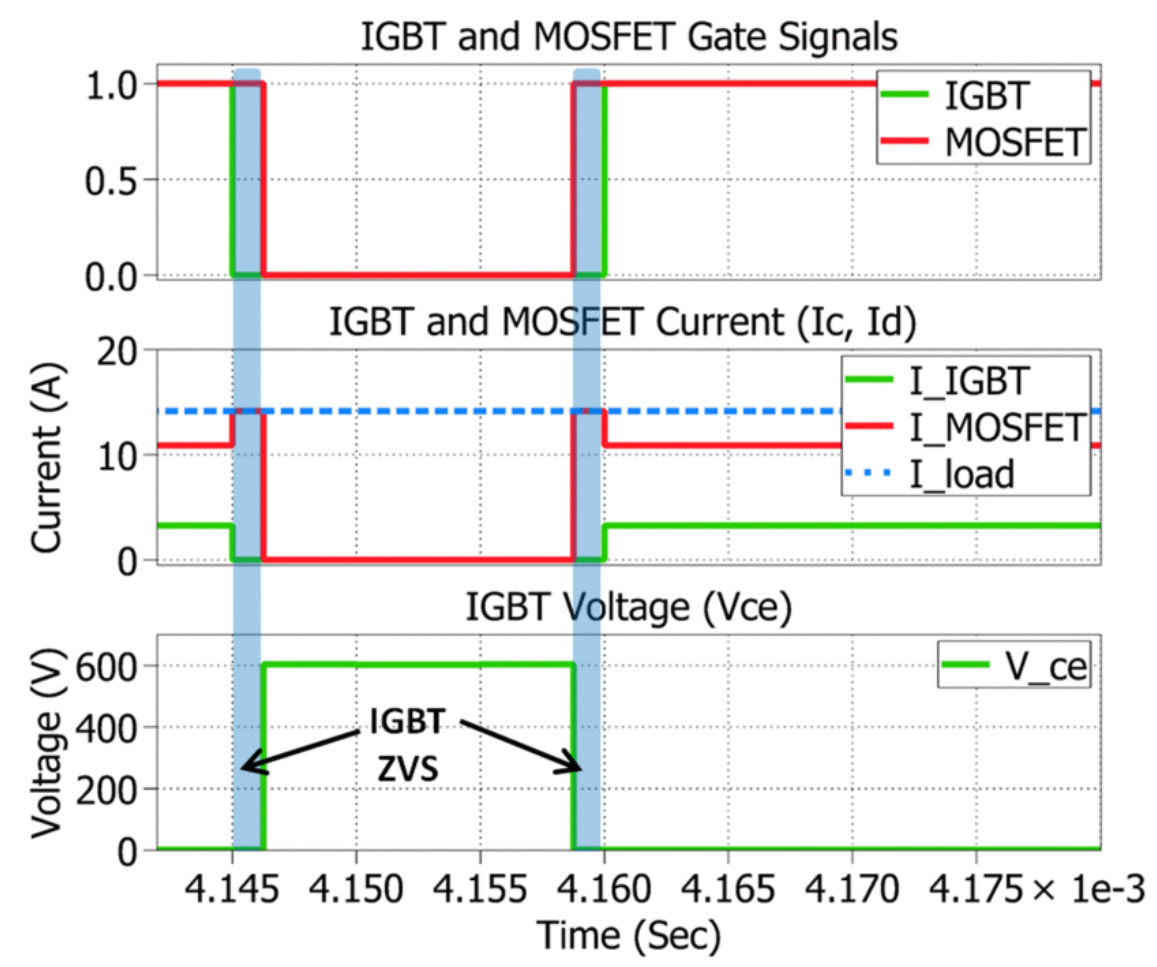

Fig. 8. Simulated ZVS operation of the IGBT in the hybrid switch at a load current of 10 A RMS ( $50 \%$ of the nominal load).

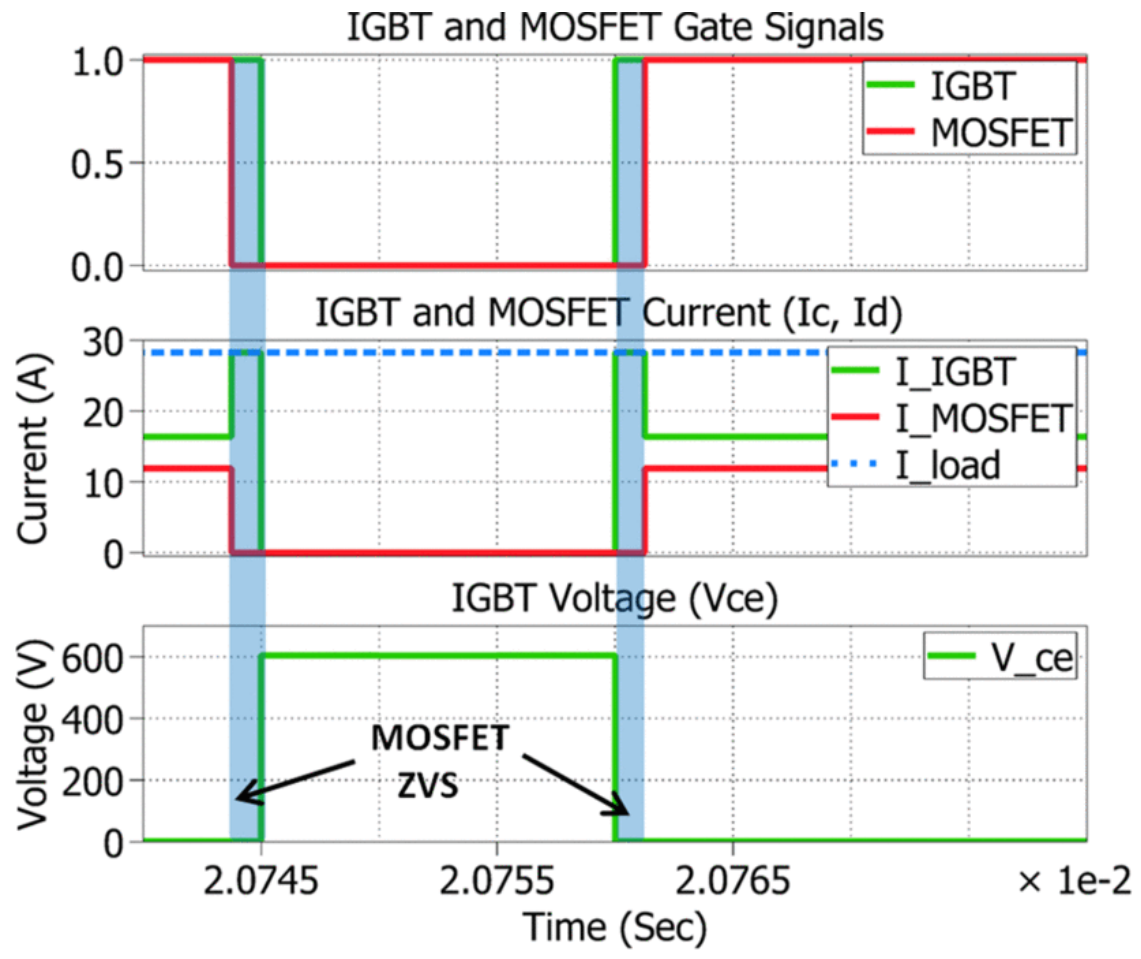

Fig. 9. Simulated ZVS operation of the SiC MOSFET in the hybrid switch at a load current of 20 A RMS (100\% of the nominal load). 


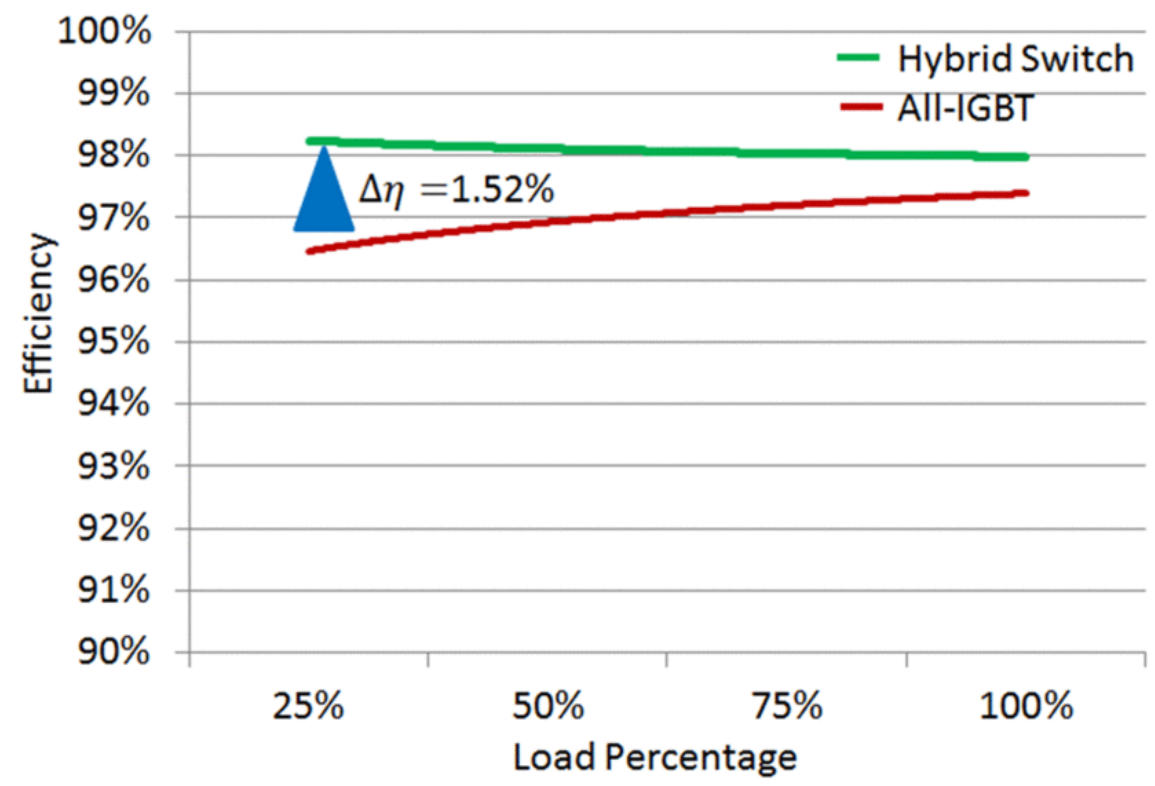

Fig. 10. Simulated efficiency comparison of the $\mathrm{H}$-bridge inverter between using the $\mathrm{Si} / \mathrm{SiC}$ hybrid switches and $\mathrm{Si}$ IGBTs (ambient temperature $T_{\mathrm{amb}}=25{ }^{\circ} \mathrm{C}, f_{\mathrm{sw}}=10 \mathrm{kHz}, f_{0}=60 \mathrm{~Hz}$ ).

\section{SECTION V.}

\section{Experimental Verifications}

In order to experimentally verify the proposed current-dependent switching strategy for the $\mathrm{Si} / \mathrm{SiC}$ hybrid switches, a 15-kW single-phase H-bridge inverter based on Si/SiC hybrid switches has been implemented in the laboratory, as shown in Fig. 11. As mentioned in Section II, an Infineon/IR IGBT (1200 V/30 A) and a CREE SiC MOSFET (1200 V/10 A) are used in the prototype to configure the $\mathrm{H}$ bridge inverter.

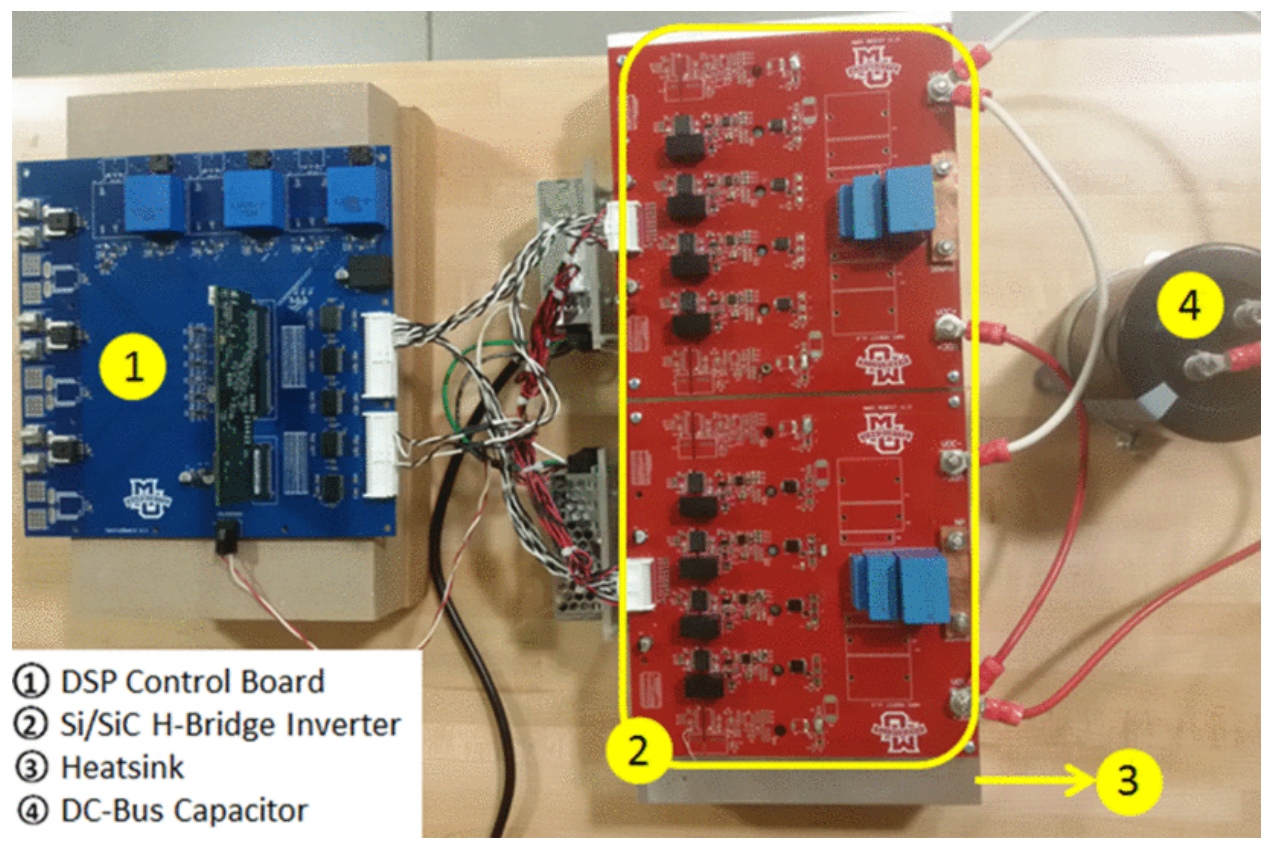

Fig. 11. Fifteen-kW single-phase H-bridge inverter based on 1200-V Si/SiC hybrid switches. 
In this prototype, there are separate gate drivers for controlling the switching of the IGBTs and the SiC MOSFETs. All the main operating parameters of the $\mathrm{H}$-bridge inverter prototype are given in Table I. In the experiments, the inverter is connected to a resistive-inductive (RL) load. The output fundamental frequency is $60 \mathrm{~Hz}$, and the switching frequency of the inverter is set at $10 \mathrm{kHz}$. The switching voltages and currents of the hybrid switch, configured by $S_{a 3}$ and $S_{a 4}$ shown in Fig. 6, are measured at various load current levels to demonstrate the efficacy of the proposed switching strategy. Fig. 12(a)- (d) shows the switching voltage and current waveforms as well as the inverter output voltage and current at a light load of 5 A RMS, which is $25 \%$ of the rated load. It can be seen in Fig. 12(a) that almost all the load current flows through the MOSFET after its turn-on while the current in the IGBT is zero. This is because that the IGBT collector-to-emitter voltage is lower than its threshold turn-on voltage. Since all the switching-on losses of the hybrid switch come from the SiC MOSFET, the losses of the hybrid switch are very low. For the switching-off process of the hybrid switch at the same light load condition, the related device voltage and currents are shown in Fig. 12(b) . In this process, the MOSFET is supposed to be turned off later to achieve ZVS turn-off of the IGBT. However, as is shown in Fig. 12(b), the later turn-off of the MOSFET caused a parasitic turn-on of the IGBT, due to the high $\mathrm{dv} / \mathrm{dt}$ generated during the MOSFET's turn-off. Such parasitic turn-on of the IGBT occurs because the high dv/dt across the IGBT charges its Miller capacitor and subsequently boosts the IGBT gate-to-emitter voltage above the turn-on voltage threshold value. The related gate driver circuit showing the current charging path of the IGBT Miller capacitor is given in Fig. 13. The expression of the charging current $i_{C G}$ in the Miller capacitance caused by the high $\mathrm{dv} / \mathrm{dt}$ as well as the gate-to-emitter voltage $V_{G E}$ is given in (1) and (2) as follows:

(2) $\begin{gathered}i_{\mathrm{CG}}=C_{\mathrm{CG}} \frac{d V_{\mathrm{CE}}}{d t} \\ V_{\mathrm{GE}}=\left(R_{\text {driver }}+R_{G \text { on/off }}+R_{G \text { int }}\right) i_{\mathrm{CG}}\end{gathered}$

where $C_{\mathrm{CG}}$ is the miller capacitance, $\frac{d V_{\mathrm{CE}}}{d t}$ is the turn-off $\mathrm{dv} / \mathrm{dt}$ generated when the parallel-connected SiC MOSFET is turned off in the hybrid switch. $R_{\text {driver }}, R_{G o n / o f f}$, and $R_{G i n t}$ are the gate driver resistance, gate turn-on/turn-off resistance, and the device internal gate resistance, respectively.

TABLE I Parameters of the 15-kW H-Bridge Inverter Based on Si/SiC Hybrid Switches

\begin{tabular}{|l|c|}
\hline Parameter & Value \\
\hline DC-bus voltage & $600 \mathrm{~V}$ \\
\hline Rated power & $15 \mathrm{~kW}$ \\
\hline Rated load current (RMS) & $20 \mathrm{~A}$ \\
\hline Switching frequency & $10 \mathrm{kHz}$ \\
\hline Output fundamental frequency & $60 \mathrm{~Hz}$ \\
\hline Load resistance per phase & $15 \Omega$ \\
\hline Load inductance per phase & $900 \mu \mathrm{H}$ \\
\hline
\end{tabular}




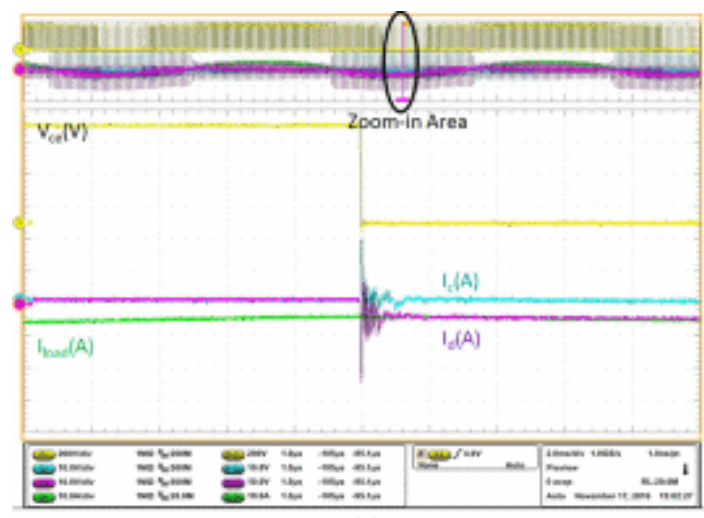

(a)

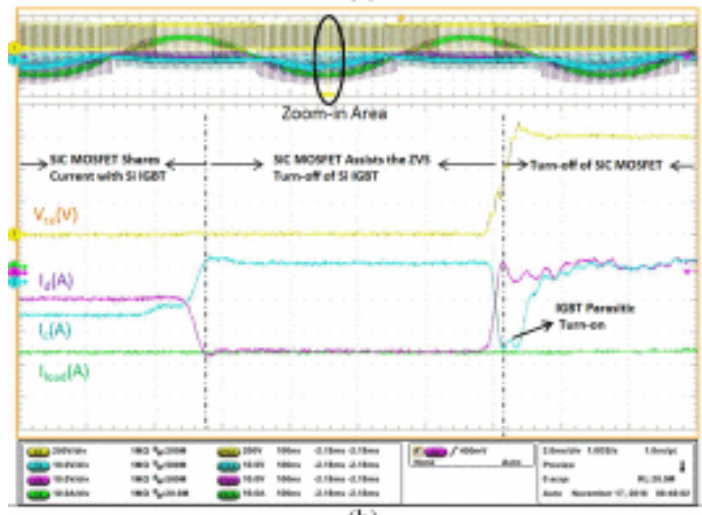

(b)

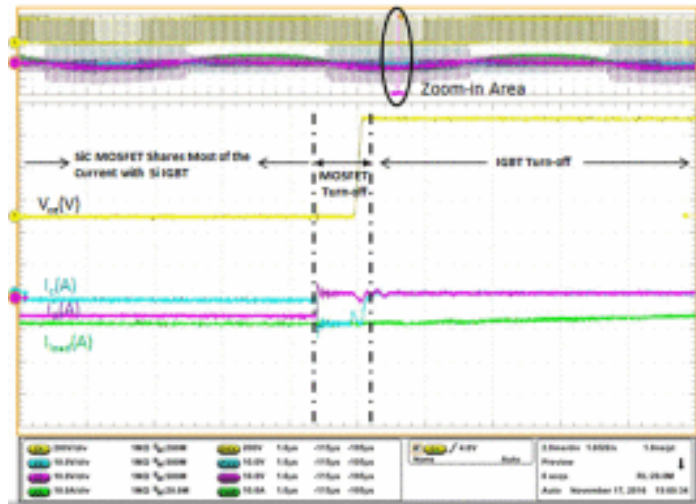

(c)

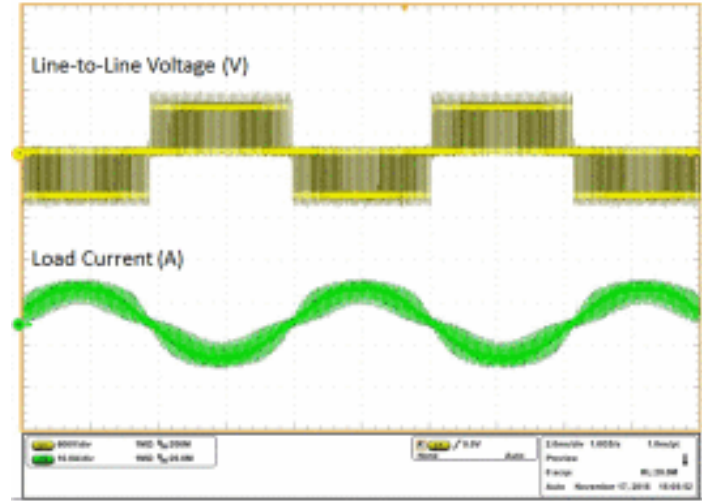

(d)

Fig. 12. Switching voltage and current waveforms of the hybrid switches and the inverter output voltage and current at a light-load current of 5 A RMS: (a) switching on (b) switching off of the hybrid switch by turning off mosfet lastly (c) switching off of the hybrid switch by turning of IGBT lastly (d) line voltage and load current. 


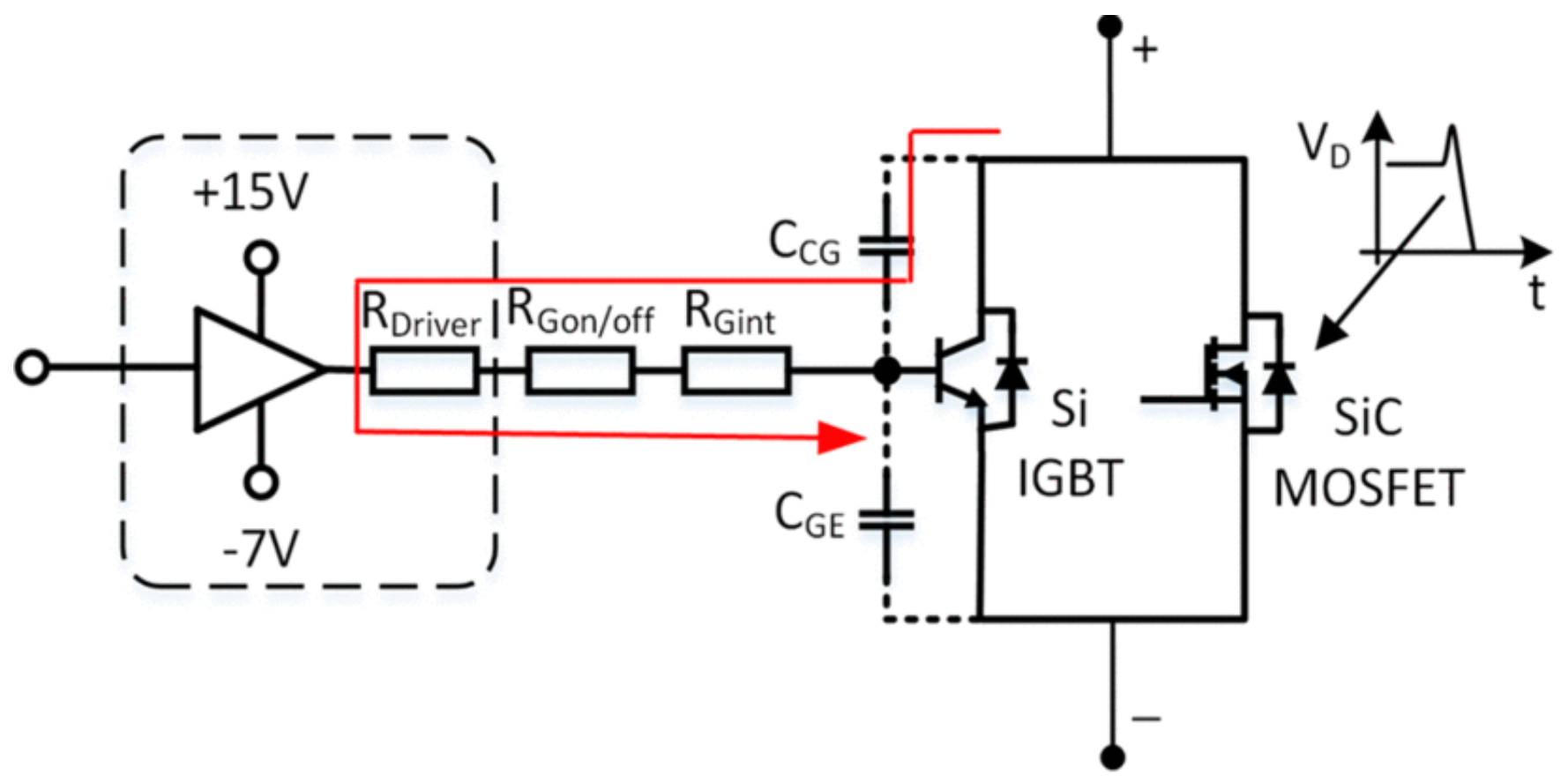

Fig. 13. Parasitic turn-on of the IGBT caused by the charging of the Miller capacitance with high dv/dt when the paralleled-connected SiC MOSFET is turned off.

It is known that the parasitic turn-on in switching devices may cause dc-bus shoot through fault if the complementary switch in a phase leg is turned on simultaneously. Therefore, here, the turn-off of the hybrid switches has to be changed into the pattern in which the SiC MOSFET is turned off earlier than the IGBT, as shown in Fig. 12(c). Such switching pattern is to avoid the parasitic turn-on of the IGBT but at the cost of more IGBT switching-off losses, compared to the ZVS soft-switching simulation results shown in Fig. 8. However, new gate drivers integrated with active Miller clamping circuit will be developed in future work to prevent the undesired parasitic turn-on. Finally, the inverter line voltage and current under such switching pattern are shown in Fig. 12(d).

Similarly, the device switching voltage and current waveforms at a medium load condition, i.e., $50 \%$ of nominal load, are shown in Fig. 14(a)- (c). As depicted in Fig. 14(a), the SiC MOSFET is turned on earlier than the IGBT, which provides a quasi-zero voltage for the turn-on of the IGBT. In other words, the IGBT will experience a quasi-ZVS turn-on. After the IGBT is fully turned on, the total load current will be shared by the two devices. Fig. 14(b) shows the switching-off voltage and current waveforms of the hybrid switch. It can be seen that the MOSFET is turned off prior to the IGBT to avoid the parasitic turnon issue. 


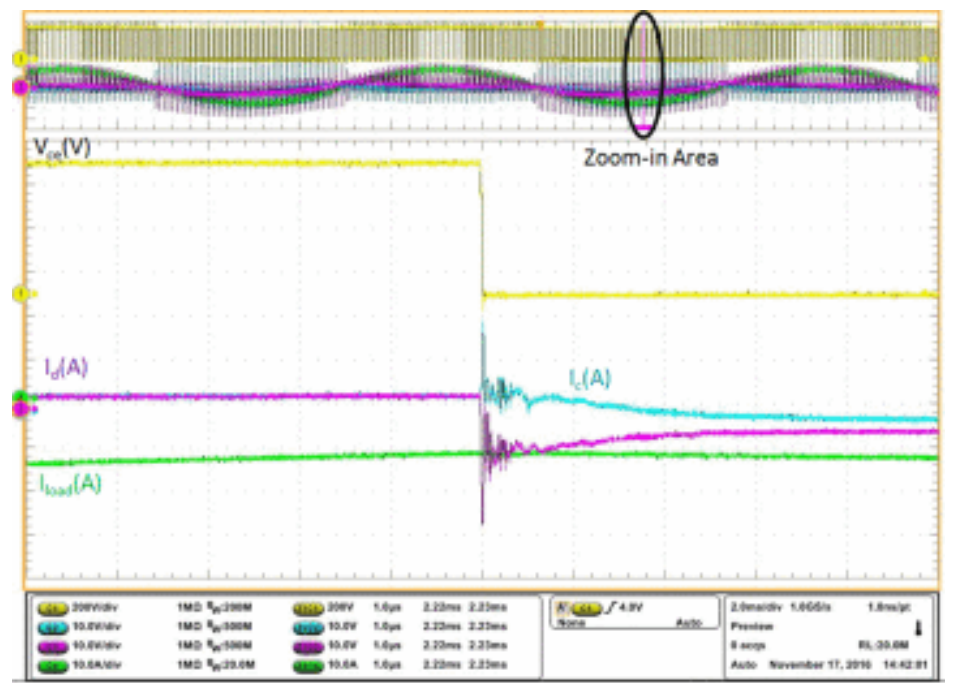

(a)

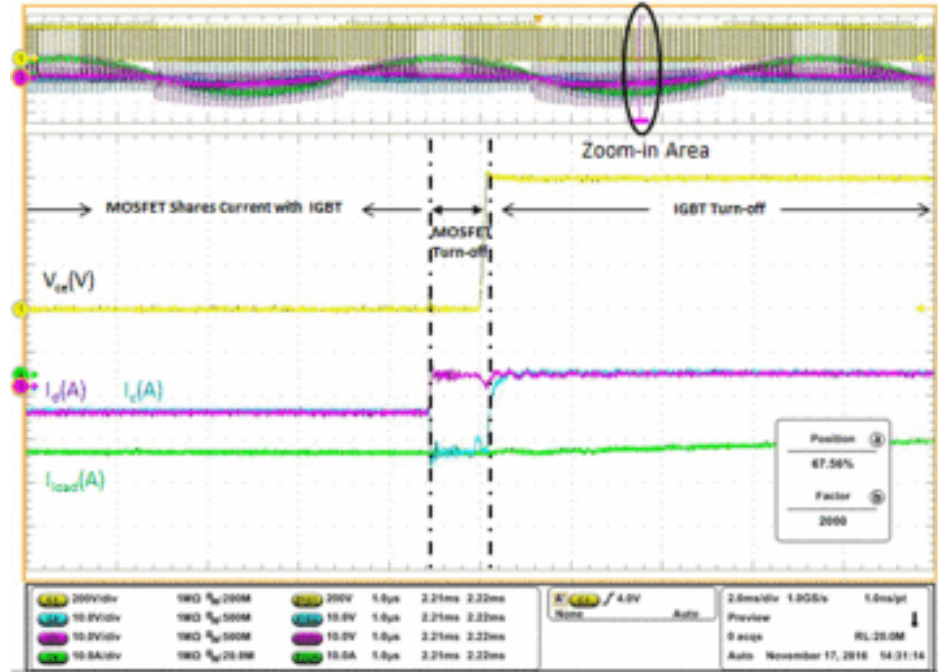

(b)

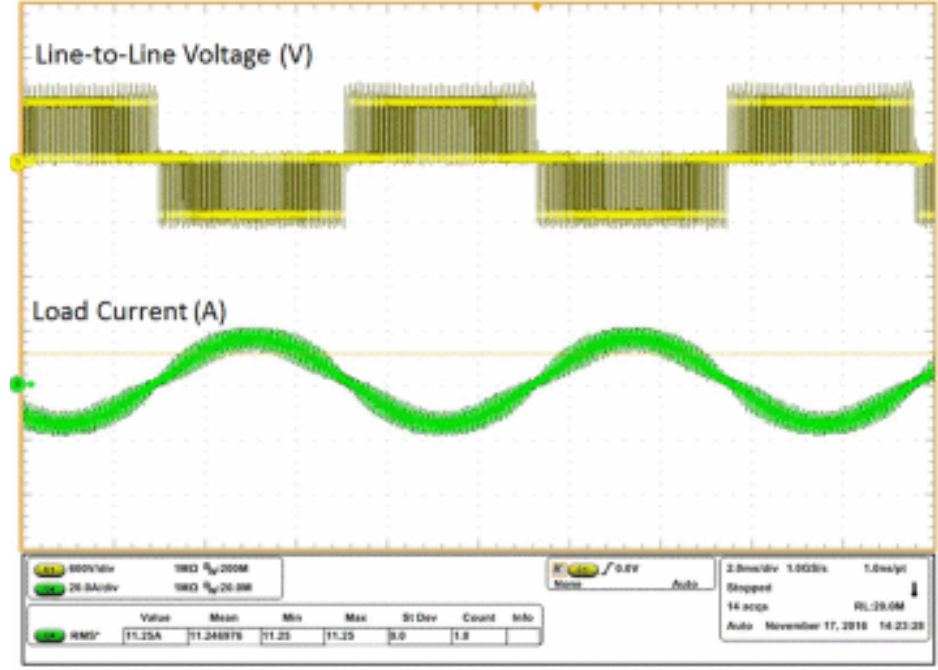

(c)

Fig. 14. Switching voltage and current waveforms of the hybrid switches and the inverter output voltage and current at a medium-load current of 10 A RMS: (a) switching on, (b) switching off, (c) line voltage and load current. 
Likewise, the switching voltage and current waveforms of the hybrid switch and the inverter line voltage and current at $100 \%$ load is shown in Fig. 15(a)- (c). Specifically, in Fig. 15(a), the prior turn-on of the SiC MOSFET is indicated by the MOSFET drain current which is equal to the total load current at the prior turn-on instant. Thus, when the IGBT is subsequently turned on, the collector-emitter voltage is almost zero, enabling a ZVS turn-on of the IGBT. When the IGBT is fully turned on, the total load current will be divided by the MOSFET and the IGBT, in which IGBT shares more current.

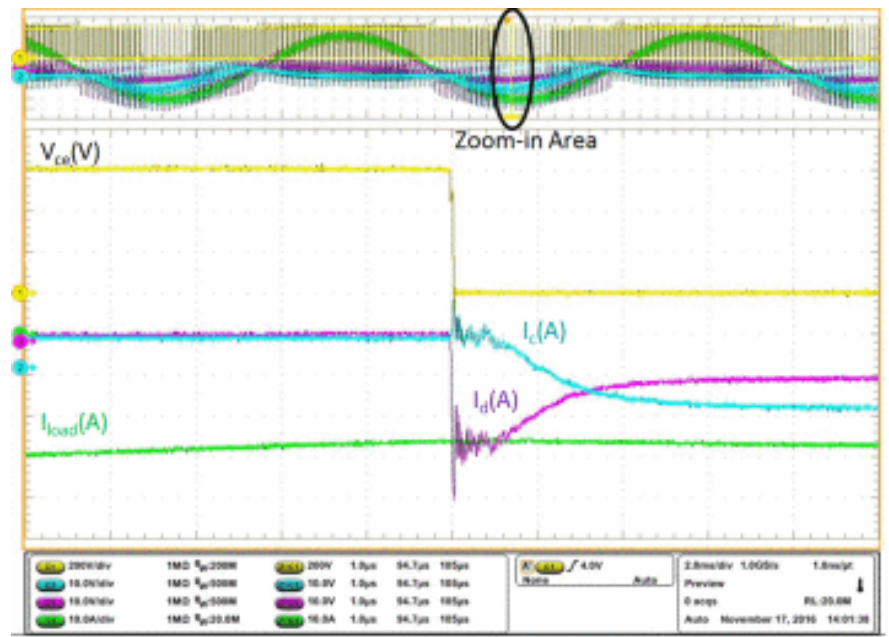

(a)

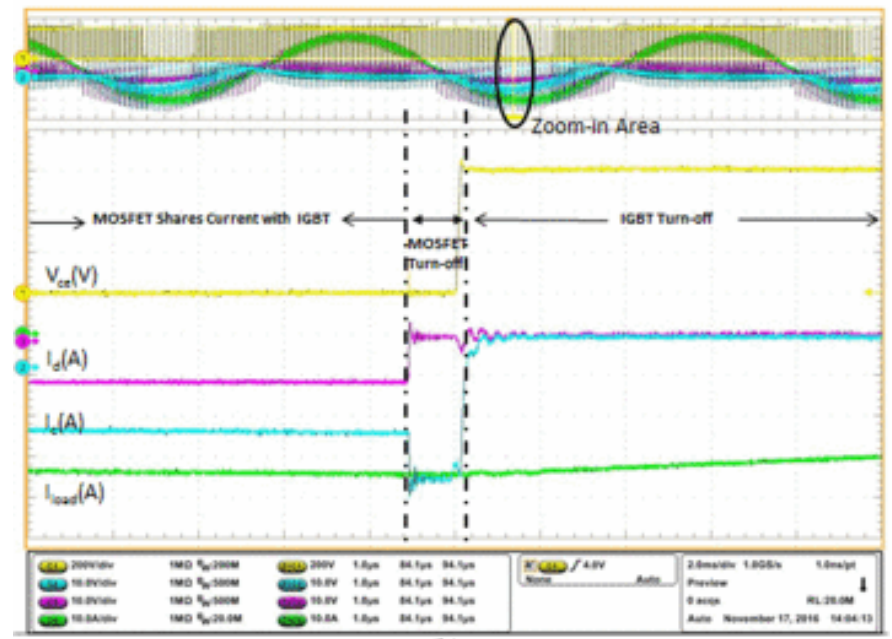

(b)

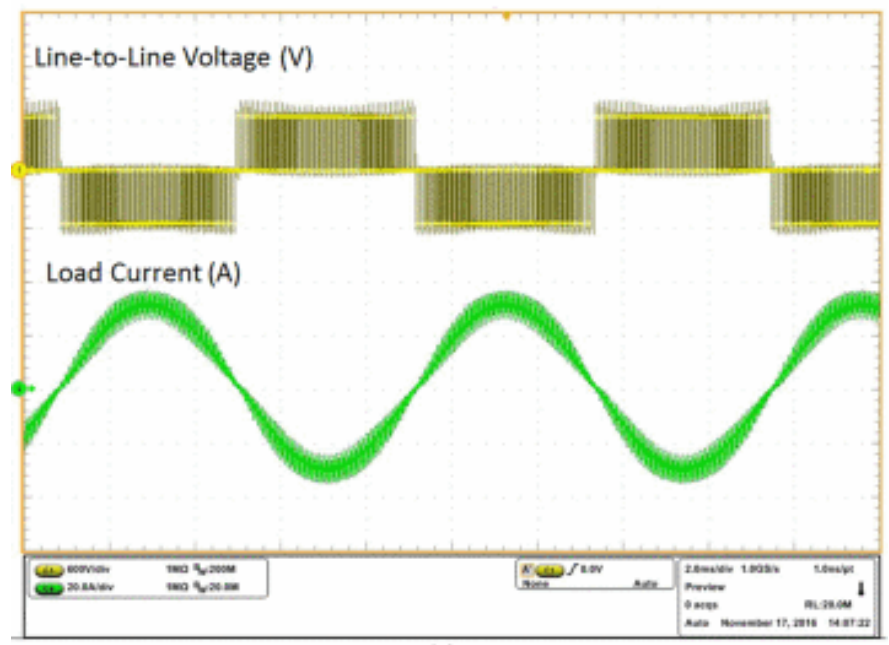

(c) 
Fig. 15. Switching voltage and current waveforms of the hybrid switches as well as the inverter output voltage and current at a nominal load current of 20 A RMS: (a) switching on, (b) switching off, (c) line voltage and current.

Without considering the parasitic turn-on issue, the switching losses of the hybrid switches is identical to the switching losses of the SiC MOSFETs during the Pattern-I and Pattern-II, and identical to the switching losses of the IGBTs during Pattern-III. Hence, to evaluate the efficiency of the 15-kW H-bridge inverter, the switching losses of the hybrid switches in the $\mathrm{H}$-bridge at load currents of 10 and $20 \mathrm{~A}$ (RMS) are measured and compared to that using pure IGBTs. The loss comparison is shown in Fig. 16(a)- (d), which demonstrates that the switching losses in the SiC MOSFET are much lower than that in the IGBT at the same switching conditions. Correspondingly, the efficiency comparison between using the hybrid switches and the IGBTs at various load levels of the H-bridge inverter is shown in Fig. 17. By comparing the efficiency curves given in Fig. 17 to the simulated efficiency curves in Fig. 10, it can be observed that the measured efficiency of the $\mathrm{H}$-bridge inverter is overall lower than the simulated efficiency. This is mainly because that the voltage and current spikes generated during the switching transients due to the parasitic commutation loop inductances were not included in the PLECS circuit thermal simulation, in which the inverter loss calculation is simply based on linear interpolation. However, at light-load and medium-load conditions, there is still significant efficiency increase up to $0.71 \%$, compared to the efficiency of the pure IGBT-based H-bridge inverter.

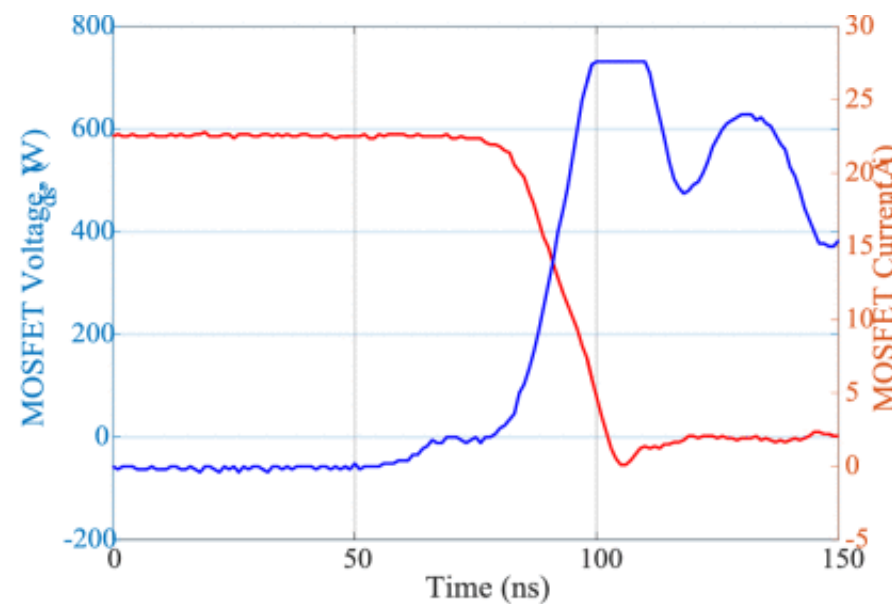

(a)

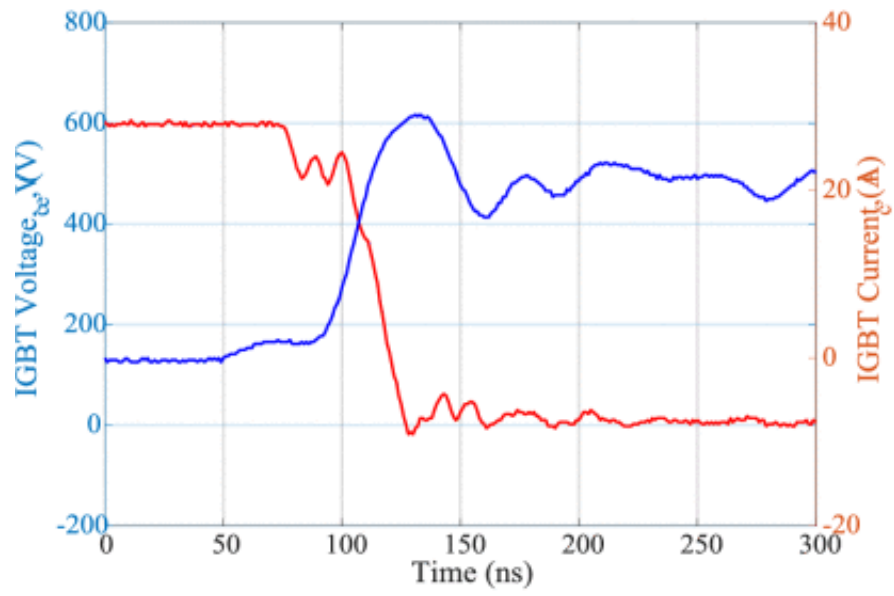

(c)

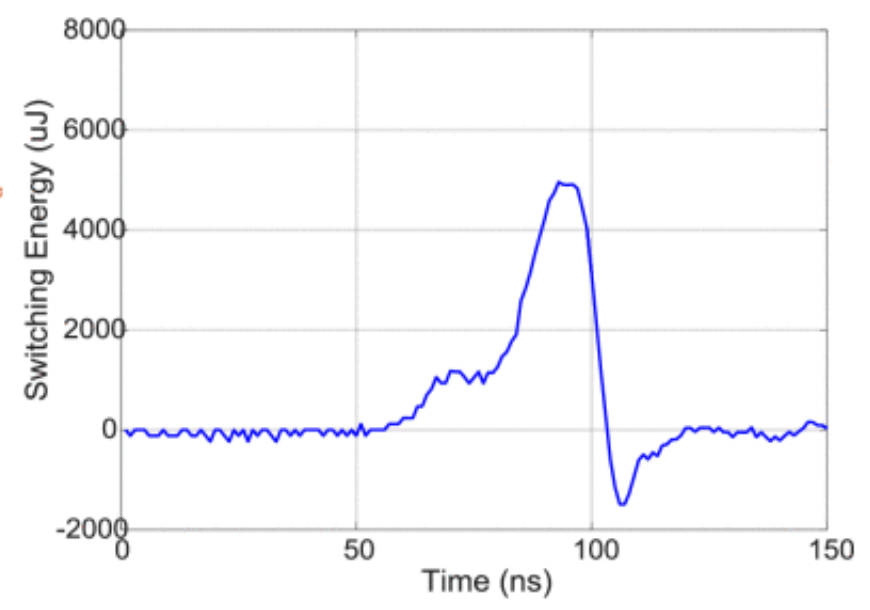

(b)

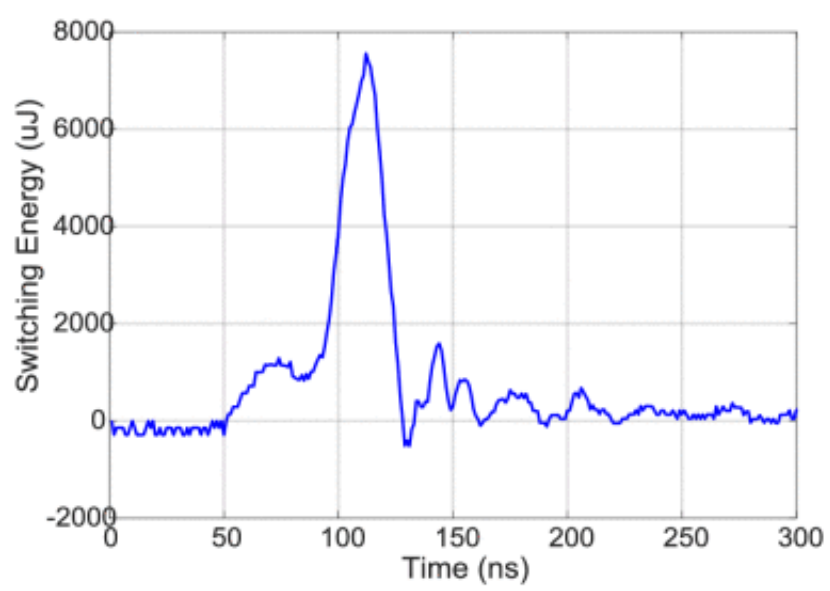

(d) 
Fig. 16. Comparison of the measured switching energies between the IGBT and the SiC MOSFET: (a) IGBT turn-on energy at $600 \mathrm{~V} / 10 \mathrm{~A}$, (b) IGBT turn-on energy at $600 \mathrm{~V} / 20 \mathrm{~A}$, (c) MOSFET turn-on energy at $600 \mathrm{~V} / 10 \mathrm{~A}$, (d) MOSFET turn-on energy at $600 \mathrm{~V} / 20 \mathrm{~A}$.

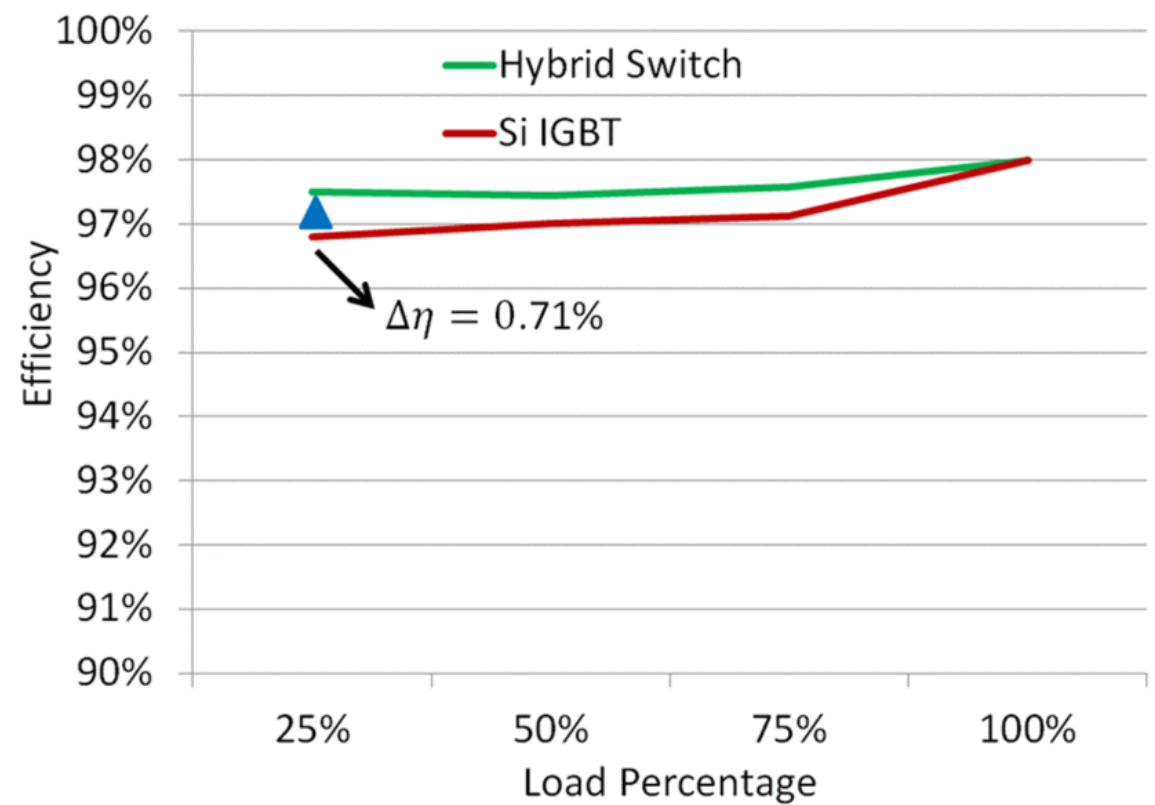

Fig. 17. Measured efficiency comparison of the 15-kW H-bridge inverter between using hybrid switches and pure IGBTs.

\section{SECTION VI.}

\section{Conclusion}

In this paper, a current-dependent switching strategy was introduced and developed for Si/SiC hybrid switches. Simulation and experiments were carried out based on a 15-kW H-bridge inverter constituted by four $1200-\mathrm{V} \mathrm{Si} / \mathrm{SiC}$ hybrid switches. This proposed switching strategy included a comprehensive consideration of reducing device losses, improving device reliability, and guaranteeing inverter overload capability. The simulation and experimental results presented above confirmed the performance of this new switching strategy for the Si/SiC hybrid switches.

Compared with conventional IGBT-based power converters, the Si/SiC hybrid switches have the following advantages:

1. much lower switching losses due to the ZVS operation;

2. higher switching frequency;

3. higher power density resulting from smaller cooling hardware design and lower filter size.

Compared with pure SiC MOSFETs or SiC JFET-based power converters, the Si/SiC hybrid switches also have the following advantages:

1. much lower cost due to fewer SiC devices required in the hybrid switch configuration;

2. larger overload capability due to the IGBT output characteristics at large current conditions. 


\section{References}

1. H. A. Mantooth, M. D. Glover, P. Shepherd, "Wide bandgap technologies and their implications on miniaturizing power electronic systems", IEEE J. Emerg. Sel. Topics Power Electron., vol. 2, no. 3, pp. 374-385, Sep. 2014.

2. J. Millan, P. Godignon, X. Perpina, A. Perez-Tomas, J. Rebollo, "A survey of wide bandgap power semiconductor devices", IEEE Trans. Power Electron., vol. 29, no. 5, pp. 2155-2163, May 2014.

3. G. Wang, F. Wang, G. Magai, Y. Lei, A. Huang, M. Das, "Performance comparison of 1200V 100A SiC MOSFET and 1200V 100A silicon IGBT", Proc. IEEE Energy Convers. Congr. Expo., pp. 3230-3234, 2013.

4. Z. Liang, P. Ning, F. Wang, "Development of advanced all-SiC power modules", IEEE Trans. Power Electron., vol. 29, no. 5, pp. 2289-2295, Feb. 2014.

5. J. J. Nelson, G. Venkataramanan, B. C. Beihoff, "Investigation of parallel operation of IGBTs", Conf. Rec. IEEE Ind. Appl. Soc. Annu. Meet. (Cat. No. 02CH37344), pp. 2585-2591, 2002.

6. N. Chen, F. Chimento, M. Nawaz, L. Wang, "Dynamic characterization of parallel-connected highpower IGBT modules", IEEE Trans. Ind. Appl., vol. 51, no. 1, pp. 539-546, Jan./Feb. 2015.

7. H. Wen, J. Liu, X. Zhang, X. Wen, "Design of high power electronic building block based on parallel of IGBTs for electric vehicle", Proc. 13th Int. Power Electron. Motion Control Conf., pp. 1518-1522, 2008.

8. J. Fabre, P. Ladoux, "Parallel connection of SiC MOSFET modules for future use in traction converters", Proc. Int. Conf. Elect. Syst. Aircraft Railway Ship Propulsion Road Vehicles, pp. 1-6, 2015.

9. C. M. Johnson et al., "Characterisation of 4H-SiC Schottky diodes for IGBT applications", Conf. Rec. IEEE Ind. Appl. Soc. Annu. Meet. World Conf. Ind. Appl. Elect. Energy, pp. 2941-2947, 2000.

10. Y. Jiang, G. C. Hua, E. Yang, F. C. Lee, "Soft-switching of IGBTs with the help of MOSFETs in bridgetype converters", 24th Annu. IEEE Power Electr. Spec. Conf., pp. 151-157, 1993.

11. J. W. Kimball, P. L. Chapman, "Evaluating conduction loss of a parallel IGBT-MOSFET combination", Conf. Proc. IEEE Ind. Appl. Soc. Annu. Meet., vol. 2, pp. 1233-1237, 2004.

12. K. F. Hoffmann, J. P. Karst, "High frequency power switch-Improved performance by MOSFETs and IGBTs connected in parallel", Proc. Eur. Conf. Power Elect. Appl., pp. 1-11, 2005.

13. J. Lai et al., "A hybrid switch based soft-switching inverter for ultrahigh efficiency traction motor drives", IEEE Trans. Ind. Appl., vol. 50, no. 3, pp. 1966-1973, May/Jun. 2014.

14. G. Ortiz, C. Gammeter, J. W. Kolar, O. Apeldoorn, "Mixed MOSFET-IGBT bridge for high-efficient medium-frequency dual-active-bridge converter in solid state transformers", Proc. IEEE 14th Workshop Control Modeling Power Electron., pp. 1-8, 2013.

15. J. He, T. Zhao, X. Jing, N. A. O. Demerdash, "Application of wide bandgap devices in renewable energy systems-benefits and challenges", Proc. IEEE Int. Conf. Renew. Energy Res. Appl., pp. 749-754, 2014.

16. T. Zhao, J. He, "An optimal switching pattern for "SiC+Si" hybrid device based voltage source converters", Proc. IEEE Appl. Power Electron. Conf., pp. 1276-1281, 2015. 
17. A. Q. Huang, X. Song, L. Zhang, "6.5 kV Si/SiC hybrid power module: An ideal next step?", Proc. IEEE Int. Workshop Integr. Power Packag., pp. 64-67, 2015.

18. M. Rahimo et al., "Characterization of a Silicon IGBT and Silicon Carbide MOSFET cross-switch hybrid", IEEE Trans. Power Electron., vol. 30, no. 9, pp. 4638-4642, Sep. 2015.

19. 2016, [online] Available: http://www.infineon.com.

20. 2016, [online] Available: http://www.wolfspeed.com/.

21. "IEEE Recommended Practice for the Application and Testing of Uninterruptible Power Supplies for Power Generating Stations," ANSI/IEEE Std 944-1986", 1986. 